\title{
Elektrikli Araçlar İçin Eksenel Akılı Çift Rotorlu Sabit Mıknatısı Senkron Motor Tasarımı ve Analizi
}

\author{
Mehmet POLAT ${ }^{1 *}$, Rüya AKINCI ${ }^{2}$ \\ ${ }^{1}$ Mekatronik Mühendisliği Bölümü, Mühendislik Fakültesi, Fırat Üniversitesi, Elazığ, Türkiye \\ ${ }^{2}$ Mekatronik Mühendisliği Bölümü, Mühendislik Fakültesi, Fırat Üniversitesi, Elazığ, Türkiye \\ 1*mpolat@firat.edu.tr, ${ }^{2}$ ruyyaakinci@gmail.com
}

Öz: Son y1llarda elektrikli araçlara olan ilgi giderek artmaktadır. Bunun en önemli sebepleri; büyük yerleşim merkezlerinde araba yoğunluğu nedeniyle oluşan çevre kirliliği, fosil yakıtların tükenmesi, dünyanın enerji kaynağı sıkıntısına girmesi, verimli ve maliyet etkin elektrikli motor ve sürücü teknolojisindeki ilerlemeler, elektrik enerjisinin depolanmasını sağlayan bataryalardaki gelişmeler ve sürüş güvenliliğinin ön plana çıkmasıdır. Elektrikli araçlarda enerji verimliliğini sağlayan en önemli etkenlerden biri motordur. Son yıllarda elektrik makineleri alanında baskın bir şekilde hâkim hale gelen sürekli mıknatıslı senkron motor sınıfindan olan eksenel akılı sürekli mıknatıslı senkron motor, diğer motor türlerine göre birçok avantaja sahiptir. Uyarma alanı olmadığından rotor kayıplarının ciddi oranda azaltılması sebebiyle verimi daha yüksektir. Ayrıca eksenel akının vermiş olduğu en büyük avantajlardan birisi yüksek güç yoğunluğudur. Kilogram başına düșen enerji (watt $/ \mathrm{kg}$ ) miktarı diğer motor türlerine kıyasla oldukça iyi seviyededir. Bu makalede öncelikle seçilen Eksenel Akılı Çift Rotorlu Sabit Mıknatıslı Senkron Motor (TORUS Tipi) hakkında literatür taraması yapılmıştır. Literatür taraması 1şığında elde edilen bilgilerle TORUS motor için bir analitik model oluşturulmuştur ve bu model optimizasyon kodlarına dökülerek Genetik Algoritma yöntemi ile optimizasyonu yapılmıştır. Yapılan optimizasyon çalışmasının çıktıları Ansys Maxwell-3D programı yardımıyla analiz edilerek doğrulanmış ve yaklaşık \%95'lik doğruluk oranı elde edilmiştir.

Anahtar kelimeler: Eksenel Akılı Çift Rotorlu Sabit Mıknatıslı Senkron Motor (TORUS Tipi), Elektrikli Araç, Genetik Algoritma, Optimizasyon, Ansys-Maxwell 3D.

\section{Design And Analysis Of Axial Flux Double Rotor Permanent Magnet Synchronous Motor For Electric Vehicles}

\begin{abstract}
In recent years there has been increasing interest in electric vehicles. The most important reasons; due to the vehicle density in large settlements resulting environmental pollution, fossil depletion of fuel to enter the world's energy supply shortages, efficient and cost advances in efficient electric motors and drive technology, advances in battery enables the storage of electrical energy and the prominence of driving safety. One of the most important factors that provide energy efficiency in electric vehicles is the motor. The axial flux permanent magnet synchronous motor, which is the permanent magnet synchronous motor class that has dominated the field of electrical machines in recent years, has many advantages over other types of motors. Since there is no excitation field, its efficiency is higher due to the serious reduction of rotor losses. In this article, a literature review was made about the selected Axial Flux Double Rotor Permanent Magnet Synchronous Motor (TORUS Type). Analytical model to literature TORUS motor scan using information obtained in the light into this model are optimized code optimization genetic algorithm method. The output of the optimization study was verified by analyzing with the help of Ansys Maxwell-3D program and accuracy rate of approximately 95\% was obtained.
\end{abstract}

Key words: Axial Flux Double Rotor Permanent Magnet Synchronous Motor (TORUS Type), Electric Vehicles, Genetic Algorithm, Optimization, Ansys-Maxwell 3D.

\section{Giriş}

Eksenel akılı sabit mıknatıslı (EASM) makineler yapı itibari ile disk şeklindedir. Temelleri 1831 yllında Faraday tarafindan tasarlanan makineye dayanmaktadır. 1837 yılında ise Davenport tarafindan radyal akılı elektromanyetik motorun patenti alınmıştır. 1889 yllında ise Nicola Tesla ilk disk şeklindeki elektromanyetik motorun patentini almıştır. Fakat sabit mıknatıslı elektrik makinelerinin gelişimi mıknatıs teknolojisindeki gelişmelere paralel olmuştur. 1931 yllında Alnico'nun keşfedilmesi, 1950 yılında baryum ferritin ve 1980'lerde özellikle neodyum demir bor materyalinin keşfedilmesi sabit mıknatıslı motorların tekrar gündeme gelmesine neden olmuştur. Ayrıca 80'li yıllardan sonra neodyum mıknatıslarının gelişimi ve fiyatlarının uygun hale 
gelmesiyle öncelikli olarak radyal akılı sabit mıknatıslı makineleri geliştirmiş ve son 10 yıldır ise EASM makineler önemli bir çalışma konusu haline gelmiştir [1].

Elektrikli araçlara olan ilginin artışı araşıımacıların elektrik makinelerinde yenilikçi araştırmalara yönelme noktasında motivasyonunu arttırmaktadır. İște bu noktada son zamanlarda elektrik makineleri alanında ön plana çıkan sürekli mıknatıslı senkron motor (SMSM) sınıfından olan eksenel akılı sürekli mıknatıslı senkron motor (EASMSM), diğer motor türlerine göre birçok avantaja sahiptir. En temel iki avantajı, verimlerinin daha yüksek olması ve yüksek güç yoğunluğudur. Bunların dışında kilogram başına düşen enerji (watt/kg) miktarı diğer motor türlerine kıyasla oldukça iyi seviyededir. Konvansiyonel radyal akılı motorlara göre daha az çekirdek malzemelerine ihtiyaç duymaktadırlar. Titreşim ve gürültü seviyesi bakımından da EASMSM motorların üstünlüğü bulunmaktadır. Dahası kolaylıkla ayarlanabilen hava aralığına sahiptirler. Doğrudan sisteme entegre olabilmesi de elektrikli araçlarda kullanım açısından önemli bir özelliktir. Özellikle teker içerisine yerleștirilmiș motor bulunan bir elektrikli araç tasarlayacak tasarımcılar için biçilmiş kaftandır denilebilir. Bir kaç Watt değerinden MW'lar seviyesine kadar EASMSM tasarımı yapılabilir. Bu motorların çıkış gücü arttıkça, rotor yüzey bağlantısı ile şaft arasındaki oran azalmaktadır. O nedenle daha yüksek güçlerin tasarımı da güçleşmektedir. Ancak bu da çoklu disk yapısı ile çözümlenmektedir.

$\mathrm{Bu}$ çalışmada, çift rotorlu EASMSM motor tasarlanmıştır bu motor literatürde TORUS motor olarak adlandırılmaktadır. Bu motorun en belirgin özelliği düşük hızlarda bile yüksek moment üretebilmesidir. Ayrıca verimleri de diğer motorlara göre daha yüksektir. Standart teker motor verimleri \%92.5-\%95 aralığında iken TORUS motorun verimi \%95- \%98 aralı̆ıında olabilmektedir ayrıca standart tip teker motorlara göre yaklaşık $\% 50$ oranında daha hafiftir [2]. Ülkemiz elektrikli araç üretimi girișiminde bulunmaktadır. Yapılacak elektrikli aracın bileşenlerinin yerli ürün olması gerekmektedir. Yapılan araştırmalar sonucunda günümüz zamanında en verimli motorların EASMSM olduğu görülmektedir.

\section{Literatür Calıșması}

Mohammad Ardebili ve Narges Taran’ in yaptığı çalışmada düşük güçte bir Eksenel Akı Sürekli Mıknatıs (EASM) senkron jeneratörü çıkış gücü ve $1 \mathrm{~kW}$ ve $100 \mathrm{~d} /$ dak' lık nominal hız genliği ile verimlilik ve güç yoğunluğunun çok amaçlı optimizasyonunu ortaya koymaktadırlar. Öncelikle, farklı EASM makine topolojilerinin kısa bir incelemesi yapılmış ve mevcut uygulama için en uygun yapı olarak çift taraflı oluklu stator (TORUS-S) yapısı seçmişlerdir. Optimizasyon problemi genel boyutlandırma denklemleri kullanılarak formüle etmiş ve daha sonra genetik algoritma (GA) kullanmıșlardır. Yenilikçi olarak, bu çalışma, objektif işlevlerin önceliğini belirlemek için bir araç sunan özgün katkı olarak yeni bir en iyileme işlevi sunmaktadır. Bu çalı̧̧ma fonksiyonu, iki değiş̧eni içerir ve bunların her ikisinde de bir artış, objektif fonksiyonların birinde diğerinden daha fazla iyileşmeye yol açar. $\mathrm{Bu}$ yöntemin esası, özellikle rüzgâr türbinlerinde kullanılan jeneratörlerdeki objektif fonksiyonların önceliklendirilmesi gereken durumlarda özellikle hissedilir, bu da sadece yüksek bir verimlilik değil, aynı zamanda düşük bir ağırlık ve hacime de sahip olmalıdır. Son olarak, sonuçlar üç boyutlu Sonlu Elemanlar Yöntemi (SEY) ile doğrulanmışlardır [3].

Harold Saavedra ve ekibi ise beş fazlı EASMSM tasarlamış ve motorun geometrik, elektrik ve mekanik parametreleri EASMSM'a dayalı yineleme yöntemi uygulayarak hesaplayıp GA ile optimizasyon işlemi gerçekleştirmişlerdir. Bu optimizasyon işleminde güç yoğunluğu ve verim fonksiyonlarını dikkate alarak tasarım yapmışlardır [4].

Peter Virtic ve ekibi çekirdeksiz tek stator ve mıknatıslı dış çift rotorlu senkron makineyi tasarım optimizasyonu, evrimsel optimizasyon kullanılarak gerçekleştirmiştir. GA ve objektif analitik değerlendirme ile fonksiyonlar sekiz değişken geometri parametresi temelinde, beş maksimumu belirlemek için objektif fonksiyonlar optimize edilmiştir. Hacim, moment yoğunluğu, ağırlık, moment yoğunluğu, en küçük hacim ve Newton-metre başına kalıcı mıknatısların ağırlığı, newton-metre başına minimum makine fiyatına göre nominal moment için optimizasyon yapılmış ve bir prototip oluşturulmuştur [5].

Solmaz Kahourzade ve ekibi EASMSM'u GA tabanlı boyutlandırma denklemleri SEY ve sonlu hacim analizi ile iki rotorlu senkron motorun ön tasarımını optimize etmişlerdir. GA Maksimum güç yoğunluğu ve en iyi ısı iletimi sonuçlarının iyileştirmek için kullanmışlardır [6].

Naghi Rostami ve ekibi eksenel akılı senkron generatör (EASG) için minimum malzeme ve maliyet durumu için en uygun tasarımı GA yardımıyla yapmışlardır. Daha sonra tasarımı doğrulatmak amacıyla generatörün 3 boyutlu eleman analizini gerçekleştirmişlerdir [7].

B. Yousefi ve ekibi yaptıkları çalı̧̧mada $1.5 \mathrm{Hp} 50 \mathrm{~V}$ 'luk EASMSM'un tasarımını yapmışlardır. Bu tasarımı yaparken en iyi yapay zeka yöntemlerinden biri olan GA optimizasyon yöntemini kullanmışlardır. Bu 
çalışma sonunda optimizasyon ve simülasyon sonucu karşıllaştırılmış ve motorun güç yoğunluğunun $\mathrm{m}^{3}$ başına 0.355 watt olduğu gösterilmiştir [8].

Chang-Chou Hwang ve ekibi SEY dayanan dahili çekirdeksiz bir stator ve harici çift rotorlu SM eksenel akılı motoru tasarlamışlardır. Motoru maximum ortalama moment, minimum ortalama moment için optimum tasarımı oluşturmuşlardır. Tasarım kriterlerini en az moment dalgalılık oranına göre en iyi kombinasyonu belirleyerek tasarımı gerçekleştirmişlerdir. Daha sonra optimize edilen motorun parametreleri 3D SEY analizi ile elde edilen parametreleri karşılaştırmış ve iki tarafın parametrelerinin uygun olduğunu görmüşlerdir [9].

M. Ardebili ve ekibi çift hava aralığı konfigürasyonuna sahip EASMSM'u yüksek güç yoğunluğu elde etmek için tasarlamış ve üretmişlerdir. Bu motorun tasarım denklemlerini incelemişlerdir. Ardından güç yoğunluğunu arttırmak amacıyla GA dayalı optimum bir tasarım sunmuşlardır. Bu optimizasyonu göstermek için iki boyutlu SEY kullanılmış ve sonuçları yapılan çalışmada sunulmuştur. Optimizasyon tekniklerine dayanarak 1 $\mathrm{kW}, 48 \mathrm{~V}, 50 \mathrm{~Hz}, 4$ kutup / 15 slotlu motoru tasarlayıp prototipini üretmişlerdir [10].

J.L. Hippolyte ve ekibi SMSM'u orjinal ve çok amaçlı bir optimizasyon tekniği kullanarak motor tasarımı yapmışlardır. Yapılan çalışma daha önceden geliştirilmiş algoritmaların daha da iyileştirilmiş halini kullanmışlardır. Bu algoritmaların verimi deterministik bir algoritma (SQP) ve bir referans çok amaçlı genetik algoritma (NSGA-II) ile karşılaştırılarak kanıtlamışlardır. Sunulan algoritma ilk olarak literatürden bir çalışma doğrultusunda doğrulanmıştır. İlk olarak slotsuz sürekli mıknatıs makinesinin boyutlandırılması. Daha sonra sürekli mıknatıslı bir motora uygulanan yöntemin deney sonuçları çok amaçlı bir bakış açısıyla vurgulanmıştır. Sürekli mıknatıslı motorlar problemi üzerine referans çoklu jenerasyon genetik algoritması NSGA-II' ye daha hızlı ve daha esnek bir alternatiftir. Bu çalışmanın ilk amacı mevcut mesafe tabanlı değerlendirme fonksiyonu ile karşılaştırmak için algoritma içinde çok amaçlı bir rekabet sürecini tasarlamaktır. İkinci amacı, algoritmanın eşzamanlı olmayan özelliklerinden yararlanarak eşler arası bir ağ üzerinde dağılımıdır[11].

Martin ve Richard çalışmalarında, bir dizi yöntemin doğrulanmasını, karşılaştırılmasını ve EASMSM'ların tasarımı ve analizi için teknikler açıklamıştır. Kompakt motor jeneratör setleri, VAWT' ler ve doğrudan sürücü uygulamaları için tekerlekli motorlar için elektromanyetik kullanımın özel bir odak noktası oluşturmuşlardır. Varsayımları değerlendirmek ve analitik yöntemlerin tahminlerini doğrulamak için SEY kullanmışlardır, dikkate alınan makinelerin elektromanyetik performansını tahmin ederek, deneysel testlerin sonuçları ve bu şekilde mevcut elektromanyetik alanları göstermektedirler. Bu çalışma, Spooner ve Chalmers'ın oluklu TORUS motorunun tasarımı ve analizi için bir dizi yöntem ve tekniğin türetilmesi, doğrulanması ve kıyaslanması ile başlamışlardır. Geliştirilen yöntemler ve teknikler daha sonra araştırmayla genişletilmiştir. Oluklu statora sahip EASMSM'ların tasarımı oluklu statorlu makineler için birleşik 2B analitik çözümden yararlanma prosedürü ile sarım geliştirilmiştir ve 40kW, 4500RPM jeneratör tasarımı için bu yaklaşım kullanılarak kompakt dizel motor jeneratör seti belirtmişlerdir. Yöntemler ve teknikler daha sonra daha da genişletilmiştir. Analitik, SEY ve deneysel yaklaşımların tüm yelpazesi gerçekleştirilerek bu yeni topoloji için kıyaslama yapılmıştır. Son olarak, farklı kutup şekilleri ve daha büyük spesifikasyonları da kapsayan VAWT jeneratörlerinin daha fazla araştırması yapmışlardır. Ayrıca, yeni EASMSM'lerin güneş enerjisiyle çalışan bir araba için bir tekerlek motoru olarak deneysel testi ve deneysel testi yapılmıştır. Bu çalışmada ele alınan EASMSM'ler sadelik, ekonomik ve montaj kolaylığı için tasarlanmıştır [12].

Christian DU-BAR yaptığı çalışmada, EASMSM'un analitik tasarımını ve SEY ile tasarımı birleştirmiştir. İlk etapta bu çalışmada iki farklı topolojinin dört farklı varyasyonu (iç rotor çift stator ve dahili statorlu çift rotor) gereksinimlere en uygun olanı ile karşılaştırılmış ve çok küçük yapısı nedeniyle stator çekirdeği oluklu olan çift rotorlu motor (YASA) seçilmiştir. Motor kutbu belirlenmiş elektromanyetik tasarım optimizasyonu oluşturulmuştur. Malzeme seçimi yapılmış SEY ile analizi gerçekleştirilmiştir. En son moment hız karakteristiğini incelemiş, tasarımı değerlendirmiş ve gelecekteki çalışmalar için önerilerde bulunmuştur [13].

Yee Pien Yang ve Guan Yu Shih dört tekerlekten çekişli bir elektrikli araç için bir EASM motorun en uygun tasarımı üzerinde çalışmalar yapmış ve önerilerde bulunmuşlardır. 3D manyetik devre modelini kullanarak motoru boyutlandırmak ve optimize etmek için kullanmışlardır. Ön tasarım için sistematik optimal tasarım süreci SEY ile doğrulandığı gibi çıkmıştır. Enerji verimliliği optimize edilerek \%15 daha verimli hale getirilmiştir. Son olarak su soğutma kanalı operasyon sırasında suyun dağıtılmasını sağlayacak şekilde tasarlanmıştır. Ayrıca, sıcaklık tepkisi ve kararlı durum sıcaklık dağılımları araştırılmış ve önerilen motorun sürekli bir sürüş modu için güvenli bir şekilde çalıştırılabileceğini kanıtlamışlardır [14].

Amin Mahmoudi ve ekibi çift rotorlu EASMSM'un iki farklı topoloji olan TORUS ve AFIR arasında bir karşılaştırma yapmışlardır. Slotlu ve slotsuz tipleri incelenmiştir. SEY kullanarak analiz yapılmıştır. Bu çalışmalarının sonucunda TORUS motor yüksek akım yoğunluğunda ve düşük elektrik yükünde yüksek güç yoğunluğunu göstermektedir. AFIR motor düşük akım yoğunluğunda ve düşük elektrik yükünde yüksek güç 
yoğunluğunu göstermektedir. Slotsuz TORUS ve AFIR AFPM makineleri slotlu modellerine göre daha düşük moment ve daha düşük moment dalgalanmasına sahip olduğunu söylemişlerdir [15].

S. Huang ve ekibi radyal akılı motorlar (RAM), enine akılı motorlar (EAM) ve eksenel akılı motorlar (EAM) hakkında araştırma yapmışlar. Araştırmalar sonunda 200 HP, 6 kutuplu 1200 dev/dak hızındaki motorun güç / moment yoğunluğunu, verimini, ısı yayılımını, ağırlık ve kullanım faktörleri açısından analizlerini gerçekleştirerek EASM motor üretmişlerdir. Oluklu ve oluksuz TORUS topolojilerinin diğer radyal ve eksenel akı topolojilerinden daha yüksek güç veya moment yoğunluk oranına sahip olduğu gözlemlemişlerdir [16].

Khwaja M. Rahman ve ekibi elektrikli araçlar için özel olarak EASM motor tasarlamış aynı zamanda bu motorun termal performansını arttırmak amacıyla soğutucu sisteminde tasarlayarak patent almışlardır. Motor üretimini gerçekleştirerek motor test sürüsslerinde 1000 milden fazla sürülmüştür ve mükemmel bir performans göstermiştir. Bu makalede tartışılan tekerlek motoru tahrikinin ölçülen performansları, sistem gereksinimleri tarafından belirlenen tasarım şartlarını karşıladı, böylece EASM makinelerinin doğrudan tahrikli otomotiv uygulamaları için güçlü adaylar olarak görülmesi gerektiğini doğruladı [17].

M. Aydin ve ekibi EASMSM'lar üzerine çalışmalarını gerçekleştirmiş̧lerdir. EASM motorların temel farklı1ıkları üzerinde durarak bu konuda ayrıntılı ve eksiksiz bir referans bölümü oluşturmuşlardır [18].

Mariusz Jagiela ve ekibi çalışmalarında, çıkıntılı kutuplu yeni bir disk tipi tek fazlı sabit mıknatıslı motor üzerine çalışmışlardır. Rotor diskindeki mıknatısların belirli bir konfigürasyonları nedeniyle, motor bir vuruntu momentini geliştirmiş̧lerdir. Aynı zamanda mevcut dalga biçimini değiştirerek sabit ve yumuşak bir moment üretebilmişlerdir. Gerekli akım dalga biçimini belirlemek için 3 boyutlu SEY kullanmışlardır [19].

Metin Aydin ve ekibi oluklu ve oluksuz TORUS motor üzerine çalışmışlardır. TORUS motorun mıknatıslarını eğimli hale getirerek ve sargı yapısını değiştirerek makineleri moment kalitesi açısından karşılaş̧ırmaları gerçekleştirmişleridir SEY ve 3D Analizlerini gerçekleştirmişlerdir [20].

J.W.K.K. Jayasundaral ve ekibi günümüzde elektrikli araç gereksinimini ve bu araçların motorundan beklenen kriterleri araştırmışlardır ve bu kriterlere en uygun motoru tasarlamışlardır [21].

DENG Qiu-ling ve ekibi elektrikli araç motorları üzerine araştırmalar yapmışlardır. Araçlar için en uygun motorun EASM motorlar olduğunu belirlemişlerdir. 6.8 KW' lık EASM motorun elektromanyetik tasarımı, analitik yöntem kullanılarak gerçekleş̧irmişler ve sonlu elemanlar yöntemi ile doğrulamışlardır [22].

Amin Mahmoudi ve ekibi EASM senkron makinenin optimize edilmiş tasarımı, performans analizi ve motor yüklü durumdayken motorun isıl analizini gerçekleştirmişlerdir [23].

Florence Libert tez çalışmasında atık su arıtımı için kullanılan mikser için $4.4 \mathrm{~kW}$ ve $50 \mathrm{rpm}$ hızında EASM tipi olan TORUS motorunun tasarımını yapmıştır. Motorun tasarımı SEY analizi ve simülasyon sonuçlarına bağlı kalınmıştır. EASM motorun sargıları üzerinde gerekli çalışmaları yaparak konsantre sargı kullanmıştır. Tasarladığı motor diğer muadillerine kıyasla yaklaşık \%50 oranında daha hafif olmuştur [24].

Thales A. C. Maia ve ekibi yenilenebilir enerji kaynakları hakkında araştırma yapmışlardır. Bu araştırmalar sonucunda rüzgâr enerjisi üzerine yoğunlaşarak TORUS generatör tasarlanmıştır. Motor tasarım aşamalarında optimizasyon ve termal analiz yapmışlardır [25].

Neethu S. Ve ekibi kan pompası uygulaması için EASMSM'un optimal tasarımını ve tasarımın geliştirilmesi üzerine çalışmışlardır. Motorun 3D SEY ile analizini gerçekleştirmişlerdir [26].

M. Fasil ve ekibi iki tekerlekli bir araç için çekiş motorunu tasarlamışlardır. Motor tipi olarak EASM'lı firçasız dc motoru seçmişlerdir. Bu çalışmada daha önce yapılan çalışmaların sentezi yapıllmış ve tasarlanacak motor için SEY analizi gerçekleştirilmiş̧ir [27].

S. Asghar Gholamian ve EASMSM'lar için iki topoloji olduğundan bahsetmiş̧lerdir. Bunlar oluklu ve oluksuz statorlu olan motor tipleridir motor boyutları denklemlerle belirlenmiş oluklu ve oluksuz olan motor tipleri karşı1laştırılmıştır. Ve sonuç olarak yüksek güçlü oluksuz EASMSM anlatılmıştır [28-29].

David A. Howey yaptığı tez çalışmasında, EASMSM'un termal analizi üzerine çalışmalarını gerçekleştirmiştir. Tez çalışmasında doğru termal analizi gerçekleştirmek için maksimum güç yoğunluğunu doğru tahmin etmenin önemli olduğuna değinmiştir. Stator konvektif 1sı transferi en önemli ve en az araştırılan 1S1 transfer mekanizmalarından biri olduğunu ve bu nedenle mevcut çalışmanın odak noktası olduğunu anlatmıştır ve bu konu hakkında çalışmalarını gerçekleştirmiştir. Çalışmalarını analizlerle desteklemiştir [30].

Rong-Jie Wang tez çalışmasında hava soğutmalı EASM jeneratörünün, demirsiz bir stator ile tasarım optimizasyonu üzerine gerçekleştirmiştir. Çok boyutlu bir optimizasyon prosedüründe SEY çözümünü doğrudan birleştiren bir tasarım yaklaşımı geliştirmiş ve $300 \mathrm{~kW}$ 'lık (birleşik güç faktörü) EASM jeneratörünün tasarım optimizasyonuna uygulamıştır. Makinenin genel tasarım optimizasyonunu sağlamak için, soğutma kapasitesi, mekanik mukavemet ve eddy kaybı gibi farklı tasarım özellikleri de bu araştırmada incelemiştir [31].

JACEK F.GIERAS ve ekibi EASM motorlar üzerine çalışma yapmışlardır. EASM motorların güç yoğunluğu diğer motorlara göre daha fazla olduğu konusuna değinmişlerdir. Bu motorların hangi alanlarda 
kullanıldığı hakkında bilgi toplamış ve bunu paylaşmışlardır. $2.7 \mathrm{~kW}$ ' lık EASM motor tasarlayarak üretimini gerçekleştirmişlerdir [32].

\section{TORUS Motorun Genetik Algoritma ile Optimizasyonu ve Tasarımı}

Eksenel akılı motor tasarımı süreci ile SM motorlar ile aynı aşamalarda gerçekleşmektedir. Diğer motor tiplerinde olduğu gibi manyetik devre analizi ile başlamaktadır. Tasarlanacak olan motorun çalışacağı kriterler doğrultusunda ön boyutlar belirlenir. Tasarım kriterleri arasında motor gücü, çalışacağı hızlar istenen verim ve maliyet gibi birçok parametrenin düşünülmesi gerekmektedir. SM motor tasarım süreçleri EA motorlar içinde tekrarlanması gerekmektedir. Şekil 1'de EA motor tasarım aşamaları gösterilmiştir.

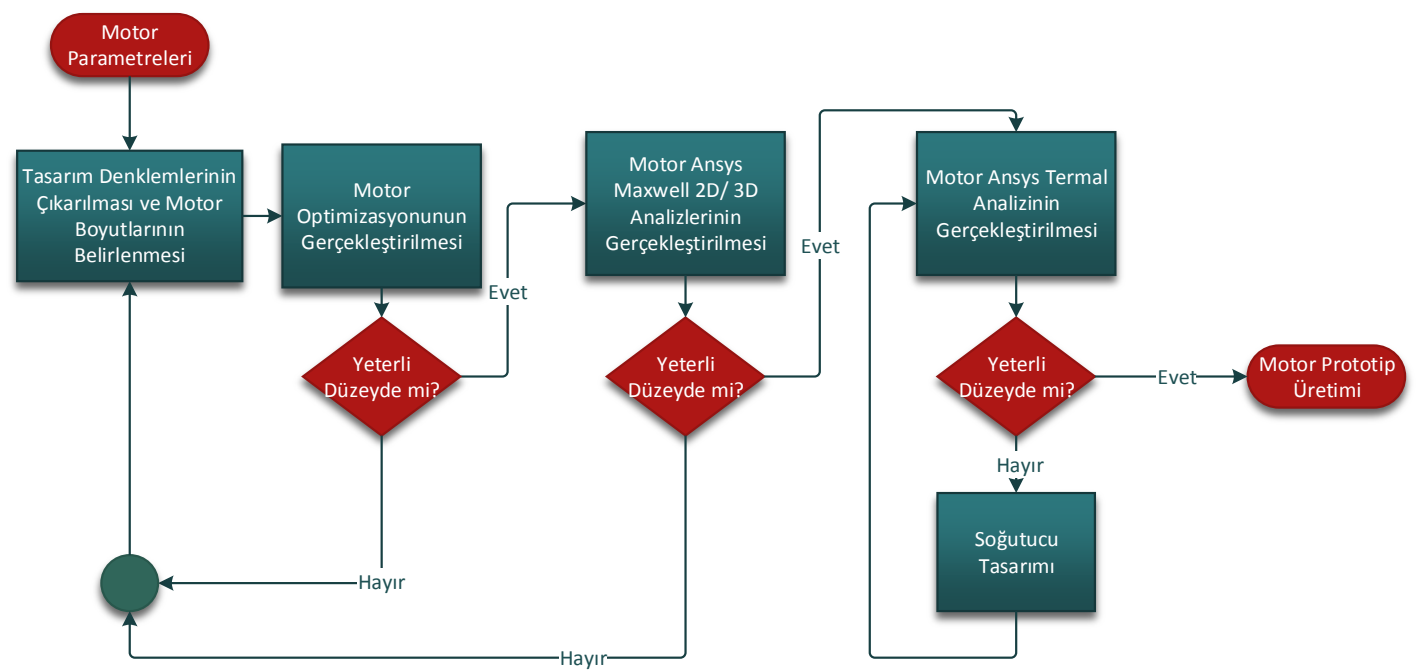

Şekil 1. Eksenel akılı motor tasarım aşamaları.

Gelen tasarım bilgileri doğrultusunda manyetik devre üzerinden bir model olușturulur, oluşturulan model üzerinden kriterler ve kısıtlamalar üzerine bir optimizasyon yapıldıktan sonra ön tasarım çalışması ortaya çıkar. $\mathrm{Bu}$ ön tasarım çalışması SEY ile elektromanyetik problem çözümü yapabilen 2D veya 3D programları ile performans eğrileri çıkartılır. Analiz çıktıları isterleri karşılamıyorsa yeniden devre modeli ve optimizasyon adımları tekrar incelenmelidir. Elektromanyetik tasarım çalışmalarını geçen tasarım yapısal analiz adımına geçebilir. Genel kullanımları direk sürüş olan EA motorlar için yapısal analiz çalışmaları önem arz etmektedir. Yapısal analiz aşamasını geçen motor tasarımı termal analiz programları kullanılarak 1sıl analizleri yapılır. Bu adımı geçemeyen tasarım için tekrar elektromanyetik tasarım tekrarlanmalıdır. EA motor tasarım süreçlerinin tüm aşamaları bitirildiğinde nihai tasarım elde edilir. Uygulamaya göre motor topolojisi belirlendikten sonra motor tasarımı için denklemler oluşturulmalı ve motor boyutlandırma problemleri çözümlenmelidir.

\section{1. Tasarım Denklemlerinin Çıkarılması}

Tasarımın birinci adımı olan tasarım denklemlerinin çıkartılması bölümü aşağıda ayrıntılı bir şekilde verilmiştir. Şekil 2'de tasarlanacak olan TORUS motorun genel hatlarını gösteren Solidworks çizimi yer almaktadır. Bu çizimdeki tanımlamalar yer alarak gerekli denklemler çıkarılmıştır.

TORUS motorlarda motorun iç çapı ile dış çapı arasında belli bir oran vardır. Bu oran Denklem 1'de ile ifade edilmiştir. Bu denklemde Lamda değeri sabit ve $\frac{1}{\sqrt{3}}$ e eşittir.

$D_{i}=\frac{D_{0}}{\text { Lamda }}$

Şekil 2'de mıknatıs çapı $D_{m o}$ ile isimlendirilmektedir. Ve mıknatıs çapının boyutunu belirleyen eşitlik Denklem 2'de verilmiştir.

$D_{m o}=D_{0}-2 h_{b}$ 


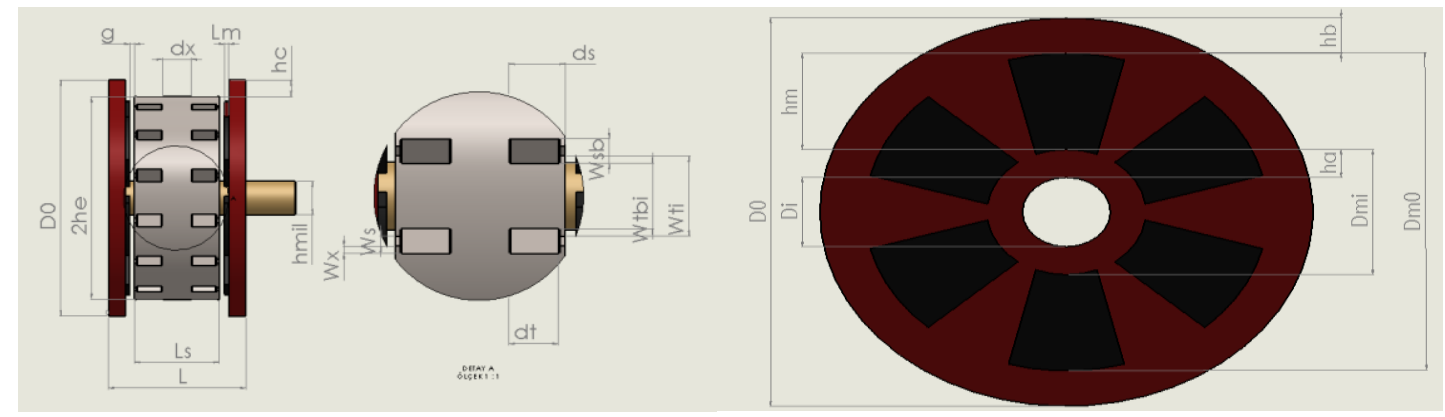

Şekil 2. Torus motor solidworks çizimi

$A_{g}$ hava aralığı alanı Denklem 3 ile hesaplanmaktadır,

$A_{g}=\frac{\pi(1+\alpha)}{2 N_{p m}}\left(D_{0}^{2}-D_{i}^{2}\right)$

Denklem 4-7 sirasıyla, $L_{y}$ statorun boyunduruk uzunluğunu, $L_{c s}$ stator yüksekliğini, $L_{s}$ toplam stator yüksekliğini ve $L$ motorun paket boyunu vermektedir,

$L_{y}=\frac{\tau_{p} B_{g}}{2 B_{\max }}$

$L_{c s}=\frac{B_{0} \pi D_{0}(1+L a m d a)}{B_{c s}{ }^{4} p}$

$L_{s}=L_{c s}+1.6 W_{c u i}$

$L=2 L_{r}+2 g+2 L_{m}+L_{s}$

Motorun manyetik devre denklemlerini çıarmak için ise Şekil 3'de yer alan manyetik eşdeğer devre kullanılmıştır.

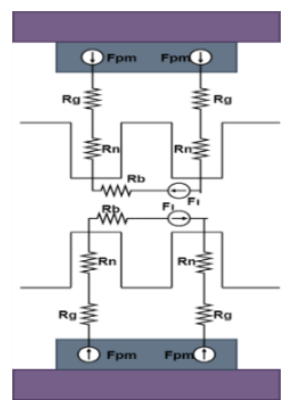

Şekil 3. Manyetik devre şeması.

Manyetik akı yoğunluğunu oluşturan manyetik alan şiddetidir. Manyetik akı yoğunluğu $\mathrm{B}\left(w e b e r / \mathrm{m}^{2}\right.$ veya Tesla) malzeme geçirgenliğine bağlıdır. Malzeme geçirgenliği $\mu_{m}$ ile ifade edilir ve birimi Henry/metre $(\mathrm{H} / \mathrm{m})$ 'dir. Malzeme geçirgenliğinin havaya göre oranı bağıl geçirgenlik $\mu_{r}$ ile ifade edilir. Ortamın geçirgenliği $\mu_{0}=4 \pi \cdot 10^{-7} \mathrm{H} / \mathrm{m}^{\prime}$ dir. Bu parametrelerin eşitlikleri Denklem 8-9'da verilmiştir. 
$B=\mu_{m} \cdot H$

$\mu_{r}=\frac{\mu_{m}}{\mu_{0}}$

Denklem 8 ve 9 dan Denklem 10 elde edilir.

$B=\frac{\mu_{m} \cdot N \cdot i}{l_{c}}$

Belirli bir alandaki manyetik akı yoğunluğu $\Phi$ (weber) Denklem 11'den hesaplanır.

$\Phi=\int_{A} B \cdot d A=B \cdot A=\frac{\mu_{m} \cdot N \cdot i \cdot A}{l_{c}}$

Sekil 3 'de verilen sabit mıknatısın ürettiği mmk Denklem 7-8-11'den elde edilerek Denklem 12' de verildiği gibidir. Denklem 12 'de $B_{r}, l_{P M}$ ve $\mu_{r, P M}$ sirasıyla sabit mıknatısın manyetik akı değeri, mıknatısın kalınlığı ve mıknatısın bağıl geçirgenliğidir.

$F_{P M}=\frac{B_{r} \cdot l_{P M}}{\mu_{r, P M} \cdot \mu_{0}}$

Denklem 13' de verilen $F_{I}$ (amper sarım) sargının ürettiği mmk'dır.

$F_{I}=N . i$

Denklem 14' de verilen formülde $B_{g 0}$ hava aralığı manyetik akı yoğunluğudur. Değeri $0.9-1$ aralığında olmalıdır.

$B_{g 0}=\frac{B_{r}}{\left(1+2 g \frac{\mu_{r}}{L_{m}}\right)}$

Denklem $15^{\prime}$ de verilen formülde $B_{g 1 p e a k}$ hava aralı̆̆ manyetik akı yoğunluğunun maksimum değeridir.

$$
B_{\text {g1peak }}=\frac{4}{\left(\pi B_{g 0} \frac{\sin \alpha_{P M}}{2}\right)}
$$

Denklem 16 'da verilen formülde $B_{m}$ mıknatıs üzerindeki akı yoğunluğudur.

$B_{m}=B_{g 0} \frac{\tau_{f}}{L_{m}}$

Motorun elektriksel devre denklemlerini çıkarmak için Şekil 4'de yer alan motorun eşdeğer devre şemasından faydalanılmıştır.

TORUS motor d eksenindeki reaktansı Denklem 17 ile ifade edilir. Denklem 17' de $X_{s d}$ d ekseni senkron reaktansıdır. $X_{a d}$ endüvi sargısının oluşturduğu reaktans, $X_{1}$ ise kaçak reaktansı ifade eder.

$X_{s d}=X_{a d}+X_{1}$

Denklem 17' yi referans alarak q ekseni için de aynı eşitlikler Denklem 18'de gösterildiği gibi verilmiştir. Formül 18 'de $X_{s q}$ q ekseni senkron reaktansıdır. $X_{a q}$ endüvi sargısının oluşturduğu reaktans, $X_{1}$ ise kaçak reaktansı ifade eder.

$X_{s q}=X_{a q}+X_{1}$ 


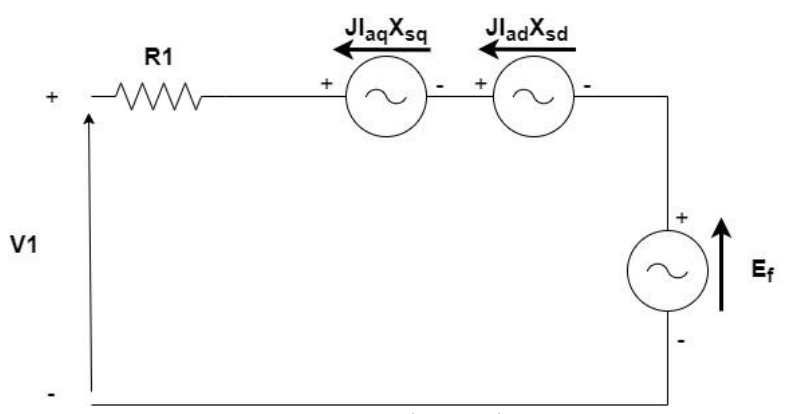

Şekil 4. Motorun eşdeğer devresi.

Denklem 17 ve $18^{\prime}$ den yararlanılarak TORUS motorun bir faz vektör diyagramı Şekil 5 'deki gibi çıkartılır.

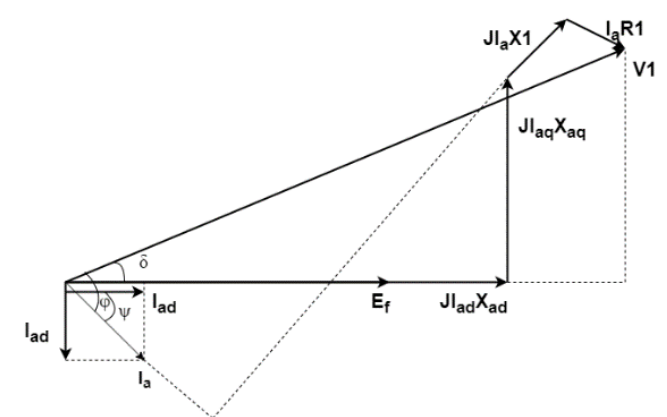

Şekil 5. TORUS motorun bir faz vektör diyagramı.

TORUS motorun bir fazı için verilen vektör diyagramından denklem 19' da verildiği gibi uygulanan gerilim eşitliği elde edilir.

$V_{1}=E_{f}+I_{a} R_{1}+J I_{a d} X_{s d}+J I_{a q} X_{s q}$

Denklem 19' da d ekseni endüvi akımı $I_{a d}$ ve q ekseni endüvi akımı $I_{a q}$ endüvi akımı $I_{a}$ cinsinden Denklem 20 ve 21 'de verildiği gibi ifade edilir.

$I_{a d}=I_{a} \sin \varphi$

$I_{a q}=I_{a} \cos \varphi$

TORUS motorda uygulanan uç geriliminin iki bileşeni Denklem 22 ve 23 'de verildiği gibidir.

$V_{1} \sin \delta=I_{a q} X_{s q}-I_{a d} R_{1}$

$V_{1} \cos \delta=E_{f}+I_{a d} X_{s d}+I_{a q} R_{1}$

TORUS motor tasarımı yapılırken motorda histerisiz $P_{h}$, eddy akımı $P_{c}$, çekirdek $P_{e}$ ve bakır kayıpları $P_{c u}$ sırasıyla Denklem 24-27 'de verilmiştir.

$P_{h}=K_{h} B_{m}{ }^{2} f$

$P_{c}=K_{c} B_{m}^{2} f^{2}$

$P_{e}=K_{e} B_{m}^{1.5}+f^{1.5}$ 
$P_{c u}=3 R_{f} I_{r m s}^{2}$

Denklem 27'deki $R_{f}$ bakır direnci, Denklem 28'deki gibi hesaplanır,

$R_{f}=\frac{\rho_{c u} L_{s} N_{t u r n}}{\frac{\pi}{4 D_{0}^{2}}}$

Bu durumda toplam çekirdek kaybı $P_{c o}$, Denklem 29'dan elde edilir,

$P_{c o}=P_{h}+P_{c}+P_{e}$

$P_{\text {in }}$ giriş gücü Denklem 30'da verilmiştir,

$P_{\text {in }}=P_{\text {out }}+P_{c u}+P_{c o}$

Son olarak motor verimi Denklem 31 ile hesaplanır

verim $=\frac{P_{\text {out }}}{P_{\text {in }}}$

Böylece genel tasarım denklemleri tamamlanmış olup, optimizasyon aşamasına geçilir.

\subsection{Genetik Algoritma ile Optimizasyonu}

Birçok pratik optimizasyon tasarım problemleri sürekli ayrık değişkenler ya da süreksiz dış bükey uzaylarla karakterize edilir. Bu tarz problemler için standart doğrusal olmayan programlama tekniklerinin kullanılması yetersiz ve maliyetli olmasına sebep olacaktır. GA bu tür problem çözümleri için uygundur ve yüksek uygunlukta küresel optimum çözüm bulunmasını sağlar [33]. GA 1970'lerde Michigan Üniversitesinde John Holland tarafından doğal sistemin adaptasyon sürecini anlamak ve doğal sistemin sağlamlığını sürdüren yapay sistem tasarlamak için geliştirilen bir algoritmadır. Günümüzde mühendislik, bilim ve işletme alanlarında yoğun olarak kullanılmaktadır. Algoritmanın temel çalışma prensibi aşağıdaki Şekil 6'da verildiği gibidir [34].

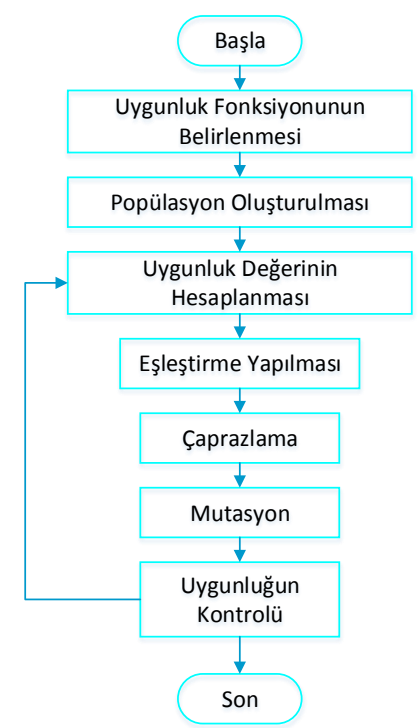

Şekil 6. Genetik algoritma akış diyagramı.

Bu çalışmada ilk olarak matlab programı üzerinde GA yöntemi kullanılarak optimizasyon çalışması gerçekleştirilmiştir. Optimizasyon çalışmasında stator iç çapı, stator dış çapı, oluk genişliği, mıknatıs yüksekliği ve oluk ağzı açıklığı belirli kısıtlamalara göre optimize edilmiştir. Optimizasyon çalışmasında fitness değeri \%90 ve üzerindeki verime göre ayarlanmıştır. Belirlenen fitness değerlerine göre optimizasyon çalışması 
gerçekleştirilmiştir. Bir sonraki adımda optimizasyon sonucunda elde edilen çıktılar optimizasyonu teyit etmek amacıyla ANSYS- Maxwell 3D programına girdi olarak yazılmıştır. Son olarak motor verimini arttırmak ve daha iyi sonuç elde etmek için ANSYS-Maxwell 3D programı üzerinden bir optimizasyon çalışması daha gerçekleştirilmiştir. Bütün bu sonuçlar Tablo 1'de karşılaştırmalı olarak yer almaktadır. Matlab üzerinde yapılan optimizasyon çalışması, ANSYS-Maxwell 3D programı ile doğrulandığında iki çalışma arasında çıkan verim değerleri arasındaki hata payı \%5.06 çıkmıştır.

Tablo 1. Torus motor optimizasyon ve analiz sonuçlarının karşılaştırılması.

\begin{tabular}{|c|c|c|c|}
\hline Parametre Adı & $\begin{array}{l}\text { Matlab } \\
\text { Optimizasyon } \\
\text { Sonuçları }\end{array}$ & \begin{tabular}{lr}
\multicolumn{2}{l}{ Optimizasyon Sonuçlarının } \\
Ansys-Maxwell & 3D \\
Üzerindeki & Doğrulama \\
Sonuçları &
\end{tabular} & $\begin{array}{lr}\text { Ansys-Maxwell } r & \text { 3D } \\
\text { Üzerinde } & \text { Yapılan } \\
\text { Optimizasyon } & \\
\text { Sonuçları } & \\
\end{array}$ \\
\hline Çıkış Gücü (W) & 4000 & 4000 & 4001.39 \\
\hline Tork (Nm) & 95.4930 & 95.5093 & 95.526 \\
\hline Hiz (rpm) & 400 & 400 & 400 \\
\hline Gerilim (V) & 400 & 400 & 400 \\
\hline Faz Akımı (A) & 14 & 18 & 16 \\
\hline Verim (\%) & 92.62 & 87.1495 & 93.0460 \\
\hline Stator Dış Çap (mm) & 250 & 250 & 250.175 \\
\hline Rotor Dış Çap (mm) & 250 & 250 & 250.175 \\
\hline Stator İç Çap (mm) & 127 & 127 & 144.439 \\
\hline Rotor İç Çap (mm) & 127 & 127 & 144.439 \\
\hline Stator Oluk Uzunluğu (mm) & 25 & 25 & 27.322 \\
\hline Stator Oluk Ağzı Genişliği (mm) & 4 & 4 & 3.52962 \\
\hline Mıknatıs Kalınlığı (mm) & 5 & 5 & 5.74743 \\
\hline Embrance (\%) & 0.99 & 0.99 & 0.781884 \\
\hline Sipir Sayısı & 142 & 142 & 142 \\
\hline Tel Çapı (mm) & 1 & 1 & 1 \\
\hline Mıknatıs Tipi & $\mathrm{NdFe} 35$ & $\mathrm{NdFe} 35$ & $\mathrm{NdFe} 35$ \\
\hline Sac Tipi & M470-50A & M470-50A & M470-50A \\
\hline Stator Dişi Akı Yoğunluğu (T) & 1.6 & 1.11889 & 1.37925 \\
\hline Stator Boyunduruk Akı Yoğunluğu (T) & 1.6 & 1.82962 & 1.93646 \\
\hline Rotor Boyunduruk Akı Yoğunluğu (T) & 1.6 & 2.00609 & 1.83109 \\
\hline Hava Aralığı Akı Yoğunluğu (T) & 0.99 & 0.736554 & 0.851925 \\
\hline Sargı Akım Yoğunluğu (A/mm²) & 5 & 5.78885 & 4.77836 \\
\hline
\end{tabular}

\section{Torus Motorun Ansys-Maxwell 3D Analiz Sonuçları}

Eksenel akılı motorların yapısı gereği manyetik analizi sadece üç boyutlu olarak yapılabilmektedir. Simetrik bir kesiti olmadığından iki boyutlu analiz için radyal akılı motorlardaki gibi kesit alınamamaktadır. Bu da hem tasarım hem de analiz sürecini uzatmaktadır. Yine de analiz süresini kısaltabilmek için motor üç boyutlu olarak simetrik parçalara ayrılmaktadır.

ANSYS Maxwell programının RMXPRT modülünde gerçekleştirilen optimizasyon sonucu elde edilen model 3 boyuta aktarılarak çözümleme yapılmıştır. Motorun ANSYS-Maxwell 3D modülünde çizilmiş modeli Şekil 7'de gösterilmektedir. 


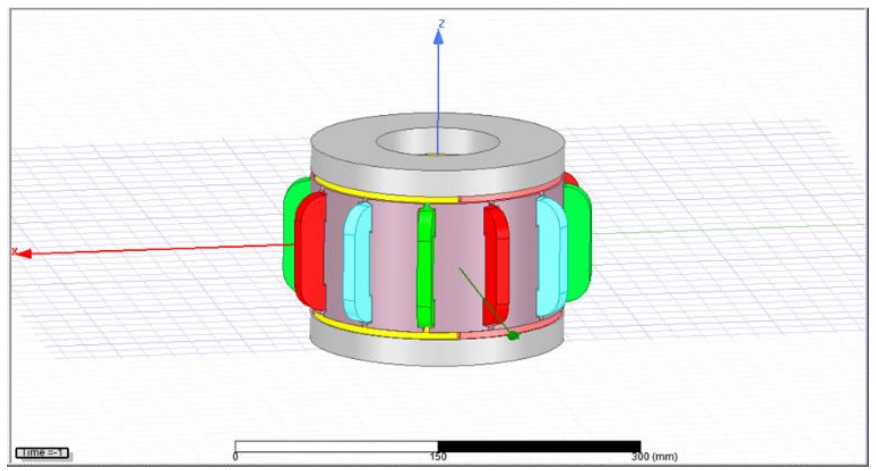

Şekil 7. Torus motor 3D çizimi.

ANSYS-Maxwell 3D analizinde tam motor analizi uzun zaman aldığından dolayı motorun sekizde biri üzerinde analiz gerçekleştirilmiştir. Motorun manyetik ak1 yoğunluğu Şekil 8a'da gösterilmiş ve motordan hedeflenen akı yoğunluğu değerlerinin elde edilmesiyle birlikte aşırı doyumlar mevcut değildir. Bununla birlikte motor modelindeki mıknatıs akı yönleri Şekil 8b' de verilmiştir.

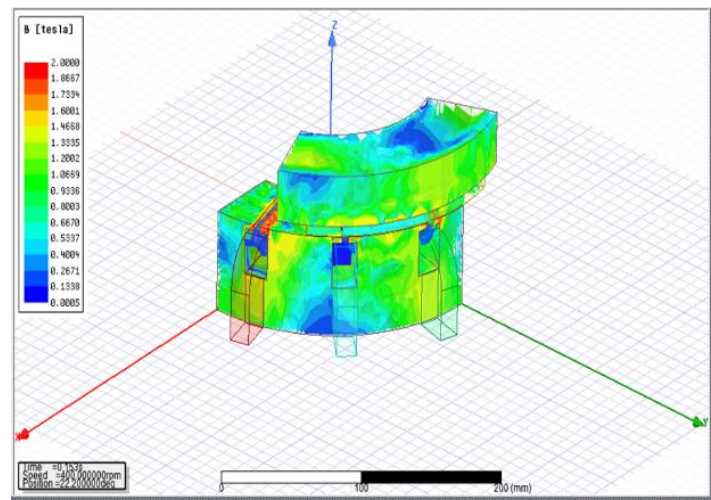

(a)

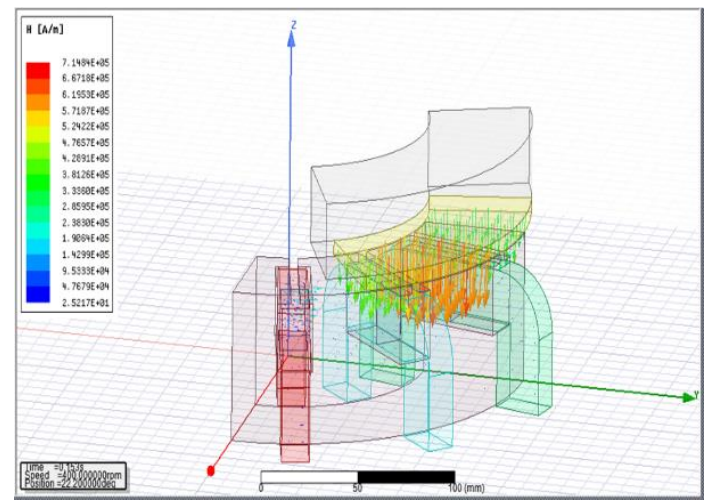

(b)

Şekil 8. a) Torus motor manyetik akı yoğunluğu. b) Mıknatıs manyetik akı yönleri.

Motor modelindeki A,B,C fazlarındaki sargıların akım yönleri Şekil 9'da gösterilmektedir. A ve B fazlarındaki akımların yönü aynı, $\mathrm{C}$ fazındaki akım yönü ise A ve B fazındaki akım yönlerinin tam tersidir.

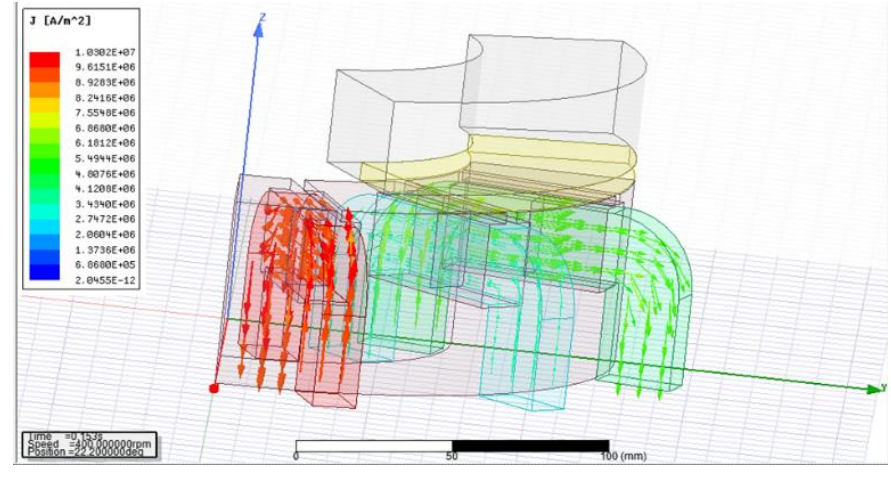

Şekil 9. Sarg1 akım yönleri.

Motor analizi sonucu elde edilen akım grafiği Şekil 10a'da görüldüğü gibidir. Etkin akım değeri hedeflenen akım değerinde olmakla birlikte yaklaşık 16 - 17 A civarlarındadır. Motor analizi sonucu elde edilen moment değeri Şekil 10b'de m1 işaretlemesiyle gösterilmiş ve değer daire içine alınmıştır. Moment değeri 94.8316 elde 
edilmiştir. Motor moment değeri hedeflendiği gibidir. Ancak moment grafiğinin dalgalılık oranı fazla çıkmıştır. Bunun sebebi motorun vuruntu momentinin yüksek olmasından kaynaklanmaktadır. Vuruntu momentini azaltma işlemi bu çalışmanın devamında yapılacaktır. $\mathrm{Bu}$ işlem rotorda mıknatısları belli bir açıda kaydırılarak gerçekleştirilecektir. Motor analizi sonucunda elde edilen çıkış gücü Şekil 10c' de m1 işaretlemesiyle gösterilmiş ve daire içine alınmıştır. Motor çıkış gücü değeri $4095.4231 \mathrm{~W}$ çıkmıştır. Motor çıkış gücü grafiğinin de dalgalılık oranının fazla çıkmasının nedeni motorun vuruntu momentinin yüksek olmasından kaynaklanmaktadır. Son olarak faz gerilim grafiği de Şekil 10d 'de verilmiştir.

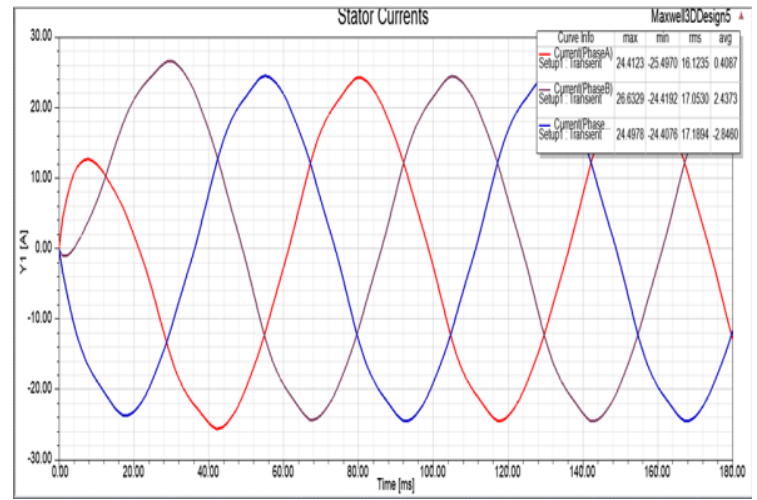

(a)

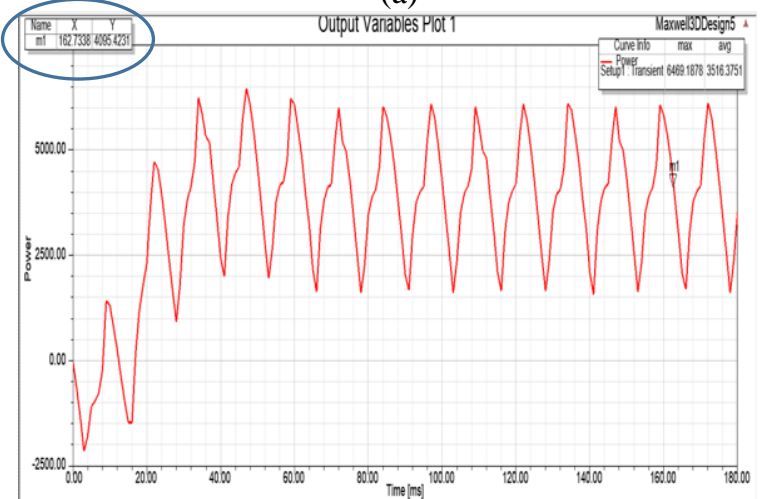

(c)

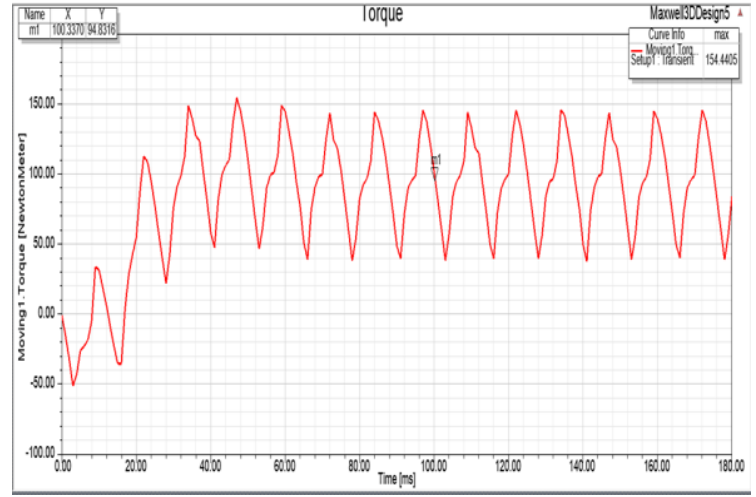

(b)

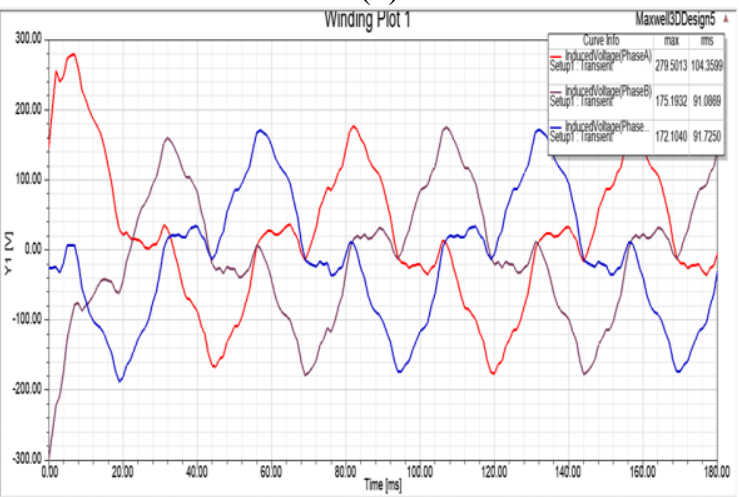

(d)

Şekil 10. a) Motor 3 faz akımı. b) Motorun üretmiş olduğu moment zaman grafiği. c) Çıkış gücü zaman grafiği. d) Üç faz gerilim grafiği.

Verim grafiği Şekil 11'de m1 işaretlemesiyle gösterilmiş ve daire içerisine alınmıştır. Elde edilen motor verimi \%93.0460’ tır.

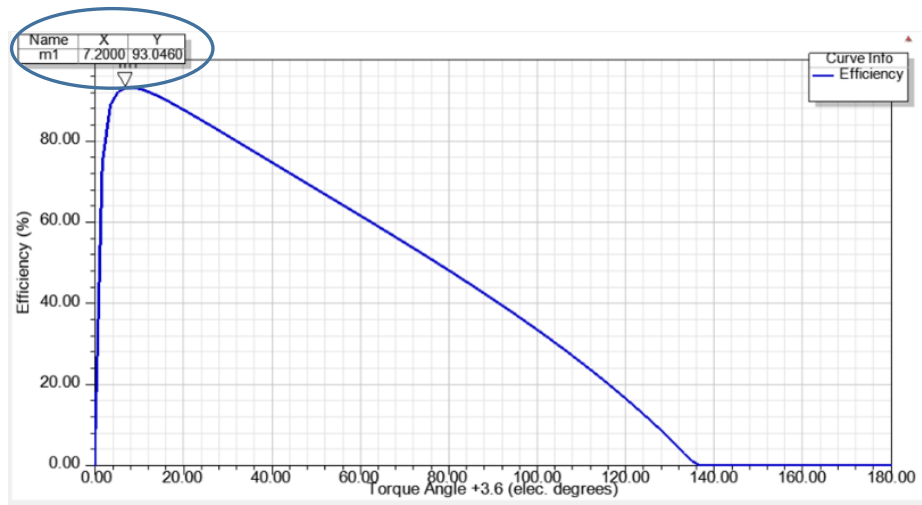

Şekil 11. Torus motorun verim grafiği. 


\section{Sonuç}

$\mathrm{Bu}$ çalışmada ilk etapta eksenel akılı sabit mıknatıslı motor sınıfindan olan TORUS motorun tasarım denklemleri çıkarılarak GA ile optimizasyon çalışması gerçekleștirilmiştir. Motor tasarım denklemlerinde motor boyutları, motor doyum oranına göre belirlenerek kütle başına maksimum güç ve verim elde edilmiştir. Çalışmanın geliştirilmesi ve doğruluğu için elde edilen sonuçlara göre ANSYS-Maxwell 3D paket programında optimizasyon geliştirmesi ve doğrulaması yapılmıştır. Yapılan çalışmalar doğrultusunda belirlenen hedeflere uygun olarak \%93.0460 verimli ve yaklaşık $4 \mathrm{~kW}$ gücünde motor elde edilmiştir. Bundan sonraki çalışmada da makalede de belirtildiği gibi moment dalgalılığının azaltılması yoluna gidilecektir.

\section{Teşekkür}

Bu çalışma 118E943 proje numarası ve "Elektrikli Araçlar için Eksenel Akıılı Çift Rotorlu Sabit Mıknatıslı Senkron Motor Tasarımı ve Üretimi” ismiyle TÜBİTAK Hızlı Destek Projesi kapsamında desteklenmiş̧ir.

\section{Kaynaklar}

[1] Hüner E. Toroidal Sargılı Açık Oluklu Eksenel Akılı Sabit Mıknatıslı NN Tip Motor Tasarımı ve Uygulaması. (Doktora tezi Marmara Üniveristesi), 2012.

[2] Libert F. Design, optimization and comparison of permanent magnet motors for a low-speed direct-driven mixer. Licentiate Thesis, Royal Institute of Technology, TRITA-ETS-2004-12, ISSN-1650-674x, Stockholm.

[3] Taran N, Ardebili M. A novel approach for efficiency and power density optimization of an axial flux permanent magnet generator through genetic algorithm and finite element analysis. 2014; IEEE 23rd International Symposium on Industrial Electronics (ISIE) (pp. 709-714). IEEE.

[4] Saavedra Ordóñez, H., Riba Ruiz, J. R., \& Romeral Martínez, J. L. Multi-objective optimal design of a five-phase faulttolerant axial flux PM motor. Advances in Electrical and Computer Engineering, 2015; 15(1), 69-76.

[5] Virtič P, Vražić M, \& Papa G. Design of an axial flux permanent magnet synchronous machine using analytical method and evolutionary optimization. 2015; IEEE Transactions on Energy Conversion, 31(1), 150-158.

[6] Kahourzade S, Mahmoudi A, Gandomkar A, Rahim N. A, Ping H. W, Uddin M. N. Design optimization and analysis of AFPM synchronous machine incorporating power density, thermal analysis, and back-EMF THD. 2013; Progress In Electromagnetics Research, 136, 327-367.

[7] Rostami N, Feyzi MR, Pyrhonen J, Parviainen A, Behjat V. Genetic algorithm approach for improved design of a variable speed axial-flux permanent-magnet synchronous generator. 2012; IEEE Transactions on Magnetics, 48(12), 4860-4865.

[8] Yousefi B, Shirazi AN, Soleymani S, Gholamian SA. Genetic algorithm application for optimum design of three phases disk type PM motor. 2012; International Journal on Computational Sciences \& Applications (IJCSA), 2(6), 1-7.

[9] Hwang CC, Li PL, Chuang FC, Liu CT, Huang KH. Optimization for reduction of torque ripple in an axial flux permanent magnet machine. 2009; IEEE Transactions on Magnetics, 45(3), 1760-1763.

[10] Gholamian SA, Ardebili M, Abbaszadeh K, Gholamian SA. Optimum design of slotted axial flux internal stator motor using genetic algorithm for electric vehicle. 2011; International Journal of Software Engineering \& Applications (IJSEA), 2(3), 87.

[11] Hippolyte JL, Espanet C, Chamagne D, Bloch C, Chatonnay P. Permanent magnet motor multiobjective optimization using multiple runs of an evolutionary algorithm. 2008; IEEE Vehicle Power and Propulsion Conference (pp. 1-5). IEEE.

[12] Richard M. Axial flux permanent magnet machines for direct drive applications. http://etheses.dur.ac.uk. 2007.

[13] Du-Bar C. Design of an axial flux machine for an in-wheel motor application. 2011; Chalmers Reproservice, Göteborg.

[14] Yang Y, Shih G. Optimal design of an axial-flux permanent-magnet motor for an electric vehicle based on driving scenarios. 2016; Energies, 9(4), 285.

[15] Mahmoudi A, Ping HW, Rahim NA. A comparison between the TORUS and AFIR axial-flux permanent-magnet machine using finite element analysis. 2011; IEEE International Electric Machines \& Drives Conference (IEMDC) (pp. 242-247). IEEE.

[16] Huang S, Aydin M, Lipo TA. A direct approach to electrical machine performance evaluation: Torque density assessment and sizing optimization. 2002; In International Conference on Electrical Machines, volume Art (Vol. 235).

[17] Rahman KM, Patel NR, Ward TG, Nagashima JM, Caricchi F, Crescimbini F. Application of direct-drive wheel motor for fuel cell electric and hybrid electric vehicle propulsion system. 2006; IEEE Transactions on Industry Applications, 42(5), 1185-1192.

[18] Aydin M, Huang S, Lipo TA. Axial flux permanent magnet disc machines: A review. 2004; In Conf. Record of SPEEDAM (pp. 61-71).

[19] Jagiela M, Mendrela EA, Wrobel R. Current control for the smoothing of torque in a single-phase permanent-magnet disc motor using 3-D FEM. 2005; Electrical Engineering, 87(4), 191-196. 
[20] Aydin M, Huang S, Lipo TA. Design and 3D electromagnetic field analysis of non-slotted and slotted TORUS type axial flux surface mounted permanent magnet disc machines. In IEMDC 2001; IEEE International Electric Machines and Drives Conference (Cat. No. 01EX485) (pp. 645-651). IEEE.

[21] Jayasundara JWKK, Munindradasa DAI. Design of multi phase in-wheel axial flux permanent magnet motor for electric vehicles. 2006; In First International Conference on Industrial and Information Systems (pp. 510-512). IEEE.

[22] Qiu-ling D, Feng X, Wen-tao H. Design of new-type axial flux permanent magnet in-wheel machine. 2010; International Conference on Electrical and Control Engineering (pp. 5831-5834). IEEE.

[23] Mahmoudi A, Kahourzade S, Ping HW, Gandomkar A. Design optimization and analysis of AFPM synchronous motor considering electrical and thermal parameters. 2013; 1st International Future Energy Electronics Conference (IFEEC) (pp. 562-567). IEEE.

[24] Libert F. Design, optimization and comparison of permanent magnet motors for a low-speed direct-driven mixer. 2004; Licentiate Thesis, Royal Institute of Technology, TRITA-ETS-2004-12, ISSN-1650-674x, Stockholm.

[25] Maia TA, Faria OA, Cardoso AA, Borges FS, Mendonça HG, Silva MA, Lopes BM. Electromechanical design for an optimized axial flux permanent magnet torus machine for 10kW wind turbine. 2011; International Conference on Electrical Machines and Systems (pp. 1-6). IEEE.

[26] Neethu S, Shinoy KS, Shajilal AS. FEA-aided design, optimization and development of an axial flux motor for implantable ventricular assist device. 2011; World Academy of Science, Engineering and Technology, 73, 93-97.

[27] Fasil M, Mijatovic N, Jensen BB, Holboll J. Finite-element model-based design synthesis of axial flux PMBLDC motors. 2016; IEEE Transactions on Applied Superconductivity, 26(4), 1-5.

[28] Gholamian SA, Yousefi A. Power density comparison for three phase non-slotted double-sided AFPM motors. 2010; Australian Journal of Basic and Applied Sciences, 4(12), 5947-5955.

[29] Gholamian SA, Ardebili M, Abbaszadeh K, Gholamian SA. Selecting of Slotted AFPM Motors with High Torque Density for Electric Vehicles. 2011; denT, 2, 4.

[30] Howey DA. Thermal design of air-cooled axial flux permanent magnet machines. 2010.

[31] Wang RJ. Design aspects and optimisation of an axial field permanent magnet machine with an ironless stator. (Doctoral dissertation, Stellenbosch: Stellenbosch University). 2003

[32] Gieras JF, Wang RJ, Kamper MJ. Axial flux permanent magnet brushless machines. 2008; Springer Science \& Business Media.

[33] Rao SS. Engineering optimization: theory and practice. John Wiley \& Sons. 2009.

[34] Mutluer M. Asenkron motor elektriksel eşdeğer devre parametrelerinin hibrid genetik algoritma yöntemiyle belirlenmesi (Doctoral dissertation, Selçuk Üniversitesi Fen Bilimleri Enstitüsü). 2007. 